\title{
Teorias (e quase teorias) da religião: um olhar descritivo
}

\author{
Theories (and quasi theories) of religion: a descriptive look
}

Osvaldo Luiz Ribeiro*

\begin{abstract}
Resumo
A partir de um recorte metodológico descritivo e de levantamento bibliográfico, na extensão que o presente instrumento de comunicação permite, o artigo apresenta um conjunto de treze teorias ou discursos sobre a religião. Mesmo quando o procedimento se revela passível de incongruência, procurou-se classificar as teorias e quase teorias em dois grupos: teorias ou quase teorias reducionistas e teorias e quase teorias não reducionistas. Foram tratadas como não reducionistas aquelas que se atêm ao conteúdo positivo da religião, sendo, por isso, classificadas como substantivas. Foram tratadas como reducionistas teorias que consideram a religião a partir de e em relação a sua expressão na sociedade, sendo também classificadas de funcionalistas. Conclui-se que, em grande medida, as teorias se sobrepõem, algumas delas constituindo desdobramentos necessários ou aprofundamentos críticos de teorias anteriores, de sorte que, em rotinas de pesquisas em Ciências das Religiões se poderiam conjugar diferentes teorias e quase teorias como quadro referencial teórico-metodológico.
\end{abstract}

Palavras-chave: Ciências da Religião; teoria da religião; teoria reducionista da religião; teoria não reducionista da religião; religião.

\begin{abstract}
From a descriptive methodological frameworkand a bibliographical survey, to the extent that the present communication instrument allows, the article presents a set of thirteen theories or discourses about religion. Even when the procedure turns out to be incongruent, we sought to classify theories and quasi theories into two groups: reductionist theories or quasitheories and non-reductionist theories and quasitheories. Theories or quasi theories that are based on the positive content of religion and are therefore classified as substantive were treated as non-reductionist. As reductionist theories or quasi theories were considered that consider religion from its expression in society, also beingclassified as functionalists. The conclusion isthat to a large extent the theories overlap, some of them constituting necessary outworkingor critical deepening of previous theories, so that, in lines of research in Religious Studiesthey could be comprisedifferent theories and quasitheories as theoretical and methodological framework.
\end{abstract}

Keywords: Religious studies; theory of religion; reductionist theory of religion; nonreductionist theory of religion; religion.

Artigo submetido em 10 de maio de 2019 e aprovado em 21 de agosto de 2019.

* Doutor em Teologia pela PUC-Rio. Professor da Faculdade Unida de Vitória. País de origem: Brasil. E- mail: osvaldo@faculdadeunida.com.br 


\section{Introdução}

Na segunda versão de seu Eight theories of religion ${ }^{1}$, Pals elabora e apresenta um sistema de classificação do conjunto das teorias e das quase teorias $^{2}$ de religião, organizadas por centros de interesse. Postulou cinco campos de interesse teórico, que chamou de "orientações", circunscrevendo a eles os teóricos clássicos: 1. orientações humanistas (Weber, Eliade, Evans-Pritchard e Geertz, dentre outros) (PALS, 2006, p. 294-295); 2. orientações psicológicas (Freud e Jung, dentre outros) (PALS, 2006, p. 295-296); 3. orientações sociológicas (Durkheim, e outros) (PALS, 2006, p. 296-297); orientações político-econômicas (Marx, e outros) (PALS, 2006, p. 297-300); e orientações antropológicas (Taylor, Frazer, dentre outros) (PALS, 20116, p. 300-304)3. Pals (2006, p. 293) chega a empregar a expressão "general patterns, or paradigms, of explanation" para descrever as abordagens dos diversos teóricos. Nesse caso, Pals considera que as orientações que ele propõe expressem a marca paradigmática do interesse do teórico marcada em sua especificidade teórico-metodológica. As distinções e diferenciações entre cada uma das teorias tratadas são, todavia, elaboradas e apresentadas nas seções anteriores da obra, onde e quando trata individualmente de oito teorias da religião. Naqueles momentos, não aplica a elas a sua sugestão de classificá-las. Seu argumento é de que são marcadas por diferentes interesses e recortes, e, de qualquer forma, representam marcos histórico-científicos do campo de pesquisa amplo dos estudos de religião e, particularmente, da discussão relacionada à teoria da religião. De qualquer forma, ainda que possa sugerir uma classificação, a apresentação que Pals faz das teorias de religião que discute segue o que se poderia chamar de modelo clássico, discutindo-as uma a uma, o que aqui se acompanha.

\footnotetext{
${ }^{1}$ A obra de Pals foi posteriormente ampliada, tendo sido traduzida e publicada no Brasil: ver Pals (2019).

"O termo "teoria" não é de todo adequado. A rigor, sejam teorias, sejam quase teorias, eventualmente representariam mais perspectivas teórico-metodológicas de acesso ao fenômeno religioso, muitas delas bastante aproximativas e mesmo parciais em sua abordagem.

${ }^{3}$ Das classificações empregadas por Pals, as aproximações antropológicas, sociológicas e psicológicas encontram eco na classificação apresentada por Eliade (1989, p. 27-38).
} 
Sem embargo de outras formas de classificação, organização e apresentação, as teorias da religião permitem-se ser divididas em dois grandes grupos. Num deles, toma-se de modo geral a religião enquanto fenômeno em si mesmo também se poderia dizer "positivamente”. No outro grupo, toma-se a religião como epifenômeno (“sometimes, religion seems epiphenomenal”) (HALL, 2003, p. 379) - também se poderia dizer "negativamente”. O mesmo se poderia dizer por meio do uso dos termos "substantivo" e "funcional", como feito no artigo de Berger (1974, p. 125-133), em cujo título se encontra a expressão "substantive versus functional definitions of religion”. O primeiro grupo tende a considerar a religião como aquilo que se revela através dos elementos que a constituem. O segundo grupo tende a reduzir teórico-metodologicamente a religião a algum aspecto assumido como relevante e determinante para a sua explicação (BERGER, 1974, p. 125) - seus teóricos são, por isso, classificados como "reducionistas", ao passo que os teóricos do primeiro grupo são considerados "não reducionistas"4.

\section{Teorias "reducionistas" da religião}

Erguendo os braços para o Céu distante e apostrofando os deuses invisíveis, os homens clamam: - "Deuses impassíveis, a quem serve o destino triunfante,

Porque é que nos criastes?! Incessante corre o tempo e só gera, inextinguíveis, dor, pecado, ilusão, lutas horríveis, num turbilhão cruel e delirante...

Pois não era melhor na paz clemente do nada e do que ainda não existe, ter ficado a dormir eternamente?

Porque é que para a dor nos evocastes?". Mas os deuses, com voz inda mais triste, dizem: - "Homens! Porque é que nos criastes?!"

(Antero de Quental. Divina Comédia)

\footnotetext{
${ }^{4}$ Deve-se ter em mente que o tratamento das teorias de religião em dois grupos, reducionistas e não reducionistas não está livre dos problemas de imbricação, já que teorias podem ser classificadas de modo bastante distinto. Pals (2006, p. 14; 149), por exemplo, classifica Marx, e ao mesmo tempo Freud e Durkheim, como "funcionalistas". Os dois primeiros seriam, respectivamente, "funcionalista psicologista" e "funcionalista economicista" (PALS, 2006, p. 14), ao passo que Freud seria representante de uma escola marcada por "functionalist reductionism" (PALS, 2006, p. 77). Por outro lado, pode-se flagrar a questão sendo tratada inteiramente sob a rubrica geral de "reducionismo funcionalista" (SILVA FILHO, 2004, p. 43).
} 
Evidentemente independentes dela, mas podendo ser apresentadas como expressões em franca coerência com a declaração de Asad (2003, p. 25) de que "não há nada essencialmente religioso, nem qualquer essência universal que define 'linguagem sagrada' ou 'experiência sagrada", as teorias ditas reducionistas da religião são aquelas que se aproximam teórico-metodologicamente da religião como um epifenômeno, isto é, um fenômeno meramente aparente e circunstancialmente secundário, situando-se o fenômeno real que corresponderia ao epifenômeno religioso em um nível antropológico, sociológico, psicológico e/ou político-econômico, por exemplo, mais profundo, portanto, e relativamente camuflado. Nas palavras de Pieper (2019, p. 15), "a religião não encontra legitimidade em si mesma", e, nas de Pals (2006, p. 77), "the reductionist approach (...) strongly insists that religion is never a reality on its own terms". É digno de nota que um dos teóricos tratados na literatura especializada como essencialista declare que "um dado religioso 'puro', fora da história, é coisa que não existe" (ELIADE, 1989, p. 22).

As teorias reducionistas da religião não partem da autocompreensão da experiência religiosa, não assumem o sentido pretendido pelos mitos, pelos ritos e pelas doutrinas religiosas, nem mesmo em termos teórico-metodológicos5. Desinteressadas de compreenderam a religião na mesma perspectiva em que a compreendem e experimentam os próprios religiosos, não constituem, consequentemente, teorias "empáticas" à religião nem assumem "positivamente" o universo religioso. Tanto é assim que "religious believers find the reductionist theories (...) generally unacceptable. In the eyes of religious faith, these approaches (...) simply misunderstand what religion at bottom is all about" (PALS, 2006, p. 114). Em sua perspectiva, as teorias reducionistas da religião buscam compreender a religião desde perspectivas críticas e confessadamente independentes da autocompreensão religiosa, o que, há de se registrar, constitui um aspecto coerente do sistema de aproximação "reducionista" ao fenômeno religioso.

\footnotetext{
${ }^{5}$ Mesmo a abordagem fenomenológica de Eliade, que até parte dos documentos religiosos, conquanto não reduza a sua hermenêutica e sistematização ao nível propositivo do seu conteúdo (ELIADE, 1990, p. 23-63).
} 


\subsection{Religião como projeção subjetiva}

Marcado por um sensível "desconhecimento" na pesquisa brasileira (SAMPAIO; FREDERICO, 2009, p. 7), um dos mais seminais críticos reducionistas da religião é Feuerbach, que se tornou filósofo após uma incursão pela teologia, que abandona (MORAIS, 2014, p. 128). A despeito de possuir uma bibliografia nada desprezível (LIMA FILHO, 2017, p. XIII-XIX), suas obras mais conhecidas e diretamente relacionadas à teoria - reducionista - da religião são "A essência do Cristianismo” (1842) e “A essência da religião” (1846).

A tese de Feuerbach é simples e fácil de ser entendida. Feuerbach afirma que a religião corresponde a um estado de alienação do homem de si mesmo (LIMA FILHO, 2017, p. 52), declaração com a qual Marx concordaria: "Feuerbach parte do fato da auto alienação religiosa” (MARX, 1979b, p. 160). Dadas as suas condições de vida, o homem tenderia a imaginar um mundo onde as vicissitudes são diferentes - melhores, naturalmente. Nesse sentido, na forma de um mundo hipostasiado, a partir de si mesmo, o homem projeta o mundo dos deuses. Projetado o mundo dos deuses na forma de um duplo do mundo real, nele se fazem habitar outros respectivos duplos - os deuses e todos os seres fantásticos dos mitos. Para Feuerbach, o mundo dos deuses e os seres celestes são duplicatas imaginárias do mundo antropológico. Nas palavras do próprio Feuerbach (2005, p. 88), "uma "fé em fantasmas".

O mundo dos deuses e os seres celestes - principalmente, os deuses constituiriam cópias “melhoradas” do mundo humano e dos próprios homens. É o que Marx leu como a tese feuerbachiana da "duplicação do mundo no mundo religioso" (MARX, 1979b, p. 160), mas, a rigor, é o que já declarava Aristóteles:

Pela mesma razão se diz que os deuses se submetiam à autoridade de um rei porque, entre os homens, uns ainda hoje são assim governados, e outros o foram antigamente. $\mathrm{O}$ homem fez os deuses à sua imagem; também lhes deu seus costumes. (ARISTÓTELES, 2010, p. 2). 
Projetados os segundos nos primeiros, os deuses são imaginados como super-humanos, vivendo como os humanos. Se os homens são bons, os deuses são superbons. Se os homens são maus, os deuses são supermaus. Se os homens são fortes, os deuses são superfortes (LIMA FILHO, 2017, p. 50-51). Nesse sentido, "Deus é, na verdade, uma espécie de "projeção" da tentação humana: o querer ser imortal, ilimitado" (LIMA FILHO, 2017, p. 50).

Produzidos pela projeção que os homens fazem de si mesmos, duplicando-se e fazendo-se habitar um mundo igualmente duplicado e imaginário, o fato de os deuses serem seres imaginários explicaria o fato de que não há atributos não humanos aplicáveis aos deuses. Por melhor que sejam, ou por pior que sejam, os deuses são, sempre, “super-homens”, no sentido de que são sempre caracterizados por qualidades e atributos humanos aumentados em intensidade e força.

Por isso, a conclusão de Feuerbach é semelhante a dizer que o homem tem o Deus que quer ter para superar a corporeidade e a natureza, a morte e a imperfeição, o que significa que, ao mesmo tempo em que é fruto da abstração, é também Deus uma necessidade afetiva do coração humano e a satisfação de sua vontade carente. (LIMA FILHO, 2017, p. 51-52).

"Em Feuerbach a teologia nada mais é do que antropologia" (RODRIGUES, 2009, p. 157). Compreender a teologia seria compreender os próprios homens, porque não há algo a se capturar lá, isto é, no mundo divino, salvo os próprios homens e o mundo humano. Para todos os fins, tratar-se-ia da "essência do homem abstraída das limitações do homem individual” (FEUERBACH, 1997, p. 57), de modo que "Deus é o conceito do gênero como se fosse de um indivíduo" (FEUERBACH, 1997, p. 194). Quando se está diante dos ritos, dos mitos, das doutrinas, está-se diante de elaborações culturais criadas como duplicações da vida e do homem, de sorte que compreender tais duplicações é compreender o próprio homem, de resto o único fenômeno real por trás da religião que, nesse sentido, constitui um epifenômeno de alienação: “a religião cristã depende da alienação em Deus dos atributos humanos concebidos de modo absoluto" (LIMA FILHO, 2017, p. 52), de sorte que a religião “permite o que a natureza e a razão negam” (FEUERBACH, 2012, p. 142). 
A alienação se daria justamente pelo fato de que, tomando o mundo divino projetado como real e mais real do que o próprio mundo humano, e passando a entender-se a si mesmo por meio do entendimento que fabrica e recebe do mundo divino projetado, o homem abandona-se a si mesmo e substitui a sua própria realidade pela não realidade da hipóstase que ele mesmo fabricara (LOPES, 2015, p. 124-135) ${ }^{6}$. A tese de Feuerbach, portanto, constitui a denúncia do "mundo religioso como reflexo ilusório do mundo terreno" (SOUZA, 2013, p. 191). A vida verdadeira não é mais a vida humana, mas a divina. E, uma vez que o homem religioso não (pode) percebe(r) isso, restaria diagnosticá-lo como vivendo em estado de alienação (UGLIK, 2010, p. 19-28), isto é, o estado de quem não compreende o que ocorre consigo mesmo, atribuindo sentidos dissonantes ao fenômeno da existência, vestindo-a com as roupas da religião e dos deuses.

Até certo ponto, o que se vem de dizer explica em parte o confronto entre Barth e a obra de Feuerbach (RODRIGUES, 2009, p. 156-169; GLASSE, 1964, p. 69-96). Não é de se estranhar, absolutamente, a observação de "que a discordância entre eles assume grandes proporções” (RODRIGUES, 2009, p. 157). Por outro lado, o conteúdo e os argumentos da crítica feuerbachiana à religião são tão dificilmente contornáveis (RIBEIRO, 2009, p. 199-218), que mesmo a teologia se vê às voltas com a necessidade, às vezes, de, assumindo-os, contorná-los, como se poderia dizer da estratégia retórica presente na declaração de Tillich de que "Deus é símbolo para Deus" (TILLICH, s/d, p. 33). Tillich que, pouco antes de falecer, confessara ter travado em sua carreira teológica uma batalha com e contra a secularização, e que pretendia, agora, travar a mesma batalha com a História das Religiões (TILLICH, 1977, p. 108), com um movimento, assume, na prática, os postulados feuerbachianos - o discurso sobre Deus não passa de projeção simbólica -, mas apenas para, no movimento seguinte, assentar a presença inquestionável e absoluta do Ser: na fórmula citada do "teólogo da cultura”, o primeiro "Deus" é feuerbachiano, mas o segundo, barthiano. Dizer sim para Feuerbach, mas apenas para, no fundo, dizer não.

\footnotetext{
${ }^{6}$ Parece possível ouvir ecos dessa reflexão em declarações como a de Geertz: "man is an animal suspended in webs of significance he himself hasspun" (GEERTZ, 1973, p. 5).
} 


\subsection{Religião como alienação}

A teoria da religião como projeção está na base de todas as teorias reducionistas7. E é simples de entender a razão: se a compreensão da religião não é elaborada por meio do discurso da própria religião, resta reduzir a religião à condição de epifenômeno, buscando o seu fundamento no nível antropológico. Como já se disse, Feuerbach

terminou por inaugurar as bases do pensamento crítico da modernidade, com tal vigor, aliás, que se espraiou por perspectivas de pensadores tão relevantes quanto díspares como os filósofos Karl Marx [...] e [...] o fundador da psicanálise Sigmund Freud. (CAMPOS, 2014, p. 63).

Antes de analisar-se, ainda que en passant, a própria "teoria” marxiana da religião, convém observar, ainda que também brevemente, a relação entre as duas teorias - a de Feuerbach e a de Marx. E isso não por uma opção nossa - o próprio Marx escreveu "Teses sobre Feuerbach", um brevíssimo texto com 11 "teses" relacionadas à "teoria da religião" do teórico reducionista com que se justifica, algumas vezes, a ruptura entre os dois teóricos.

O tom é de ultrapassagem - isto é, Marx considera insuficiente o trabalho de Feuerbach, conquanto concorde em grande parte com o teórico: "sobre os aforismos de Feuerbach não estou de acordo apenas em um ponto, aquele no qual insiste demasiadamente sobre a natureza e muito pouco sobre a política” (MARX; ENGELS, 1980, p. 419 apud BIANCHI, 2006, p. 54). Não, todavia, pelo fato de ser tratada a religião como epifenômeno e os deuses e seu mundo como projeção, mas, basicamente, por dois elementos fundamentais: a) Feuerbach é considerado insuficientemente revolucionário (BIANCHI, 2006, p. 54) e ainda idealista (REDYSON, 2011, p. 11) e b) Feuerbach se classificaria entre os filósofos que “interpretam o mundo", quando, segundo Marx, a tarefa - agora - deve ser outra: "os filósofos apenas interpretaram o mundo de forma diferente: o que importa é mudá-lo” (MARX, 1979b, p. 161). Nas palavras do próprio Marx,

\footnotetext{
7 Considere-se, por exemplo, a declaração de Aletti $(2004$, p. 165) de constituir a abordagem freudiana na proposta de leitura da religião como "construção projetiva".
} 
Feuerbach parte do fato da autoalienação religiosa, da duplicação do mundo no mundo religioso, representado, e num real. O seu trabalho consiste em resolver o mundo religioso na sua base mundana. Ele perde de vista que depois de completado este trabalho ainda fica por fazer o principal. (MARX, 1979b, p. 160).

A partir de Feuerbach, Marx elabora sua própria leitura da religião, sem, todavia, deixar de considerar que a religião seja, para todos os fins e modos, projeção. Assim, o que é a religião não é, de fato, a divergência entre Marx e Feuerbach - mas a razão pela qual ela é projeção. Para Marx, os homens "produzem a religião, uma consciência invertida do mundo, porque são um mundo invertido" (MARX, 1979a, p. 93). Para Marx, trata-se de uma "fuga", ainda que uma fuga sem sair do lugar, mas facultada pela conformação ao status quo, isto é, "a condição dada por uma consciência, que permite ao indivíduo conformar-se com a sua realidade" (ALVES SÁ, 2012, p. 78). A fuga, todavia, estaria diretamente ligada às condições materiais e objetivas da vida. A vida humana dá-se nas condições sociais e políticas concretas. Sua felicidade e dor são produtos das condições materiais da vida: as condições de subsistência e de trabalho: "'a alienação do trabalho' como a raiz de todo o complexo de alienações" (MÉSZÁROS, 2006, p. 21).

Não se trata, apenas, de o homem entender de modo mágico e equivocado a sua existência. Não é apenas o seu entendimento da vida que está deslocado - sua própria vida está deslocada. Sua condição de trabalho constitui o caso de alienação por excelência. $\mathrm{O}$ homem não vive mais para si, não trabalha mais para si, não dispõe mais de si mesmo - antes, vive, trabalha e dispõe-se para outros homens. Estes são os detentores dos regimes e dos mecanismos de produção, do capital e, em última análise, das leis que legitimam e justificam o status quo. Sendo assim, o programa revolucionário a que tal crítica está vinculado prescreve:

é que o fato de esta base mundana se destacar de si própria e se fixar, um reino autônomo, nas nuvens, só se pode explicar precisamente pela autodivisão e pelo contradizer-se a si mesma desta base mundana. É esta mesma, portanto, que tem de ser primeiramente entendida na sua contradição e depois praticamente revolucionada por meio da eliminação da contradição. (MARX, 1979b, p. 160). 
Deslocado de si mesmo, sem o poder de autogestão, sem possuir os regimes e os instrumentos de seu próprio trabalho, tornado ele mesmo um equipamento do mecanismo de acúmulo de capital, o homem vive em constante sofrimento material e, por isso, mental e “espiritual”. É para mitigar esse sofrimento, alimentando esperanças de um futuro melhor, que a religião é praticada, funcionando, a partir daí, nos mesmos moldes propostos por Feuerbach - projeção antropológica. Tratase, todavia, de uma projeção que tem a função de entorpecer a consciência da alienação, tornando-a, de um lado, camuflada e, de outro, suportável. É nesse contexto que Marx escreve a famosa frase, na qual faz a religião equivalente ao entorpecente que marcou as relações políticas, econômicas, militares e sociais entre a Inglaterra e a China de seu tempo:

A miséria religiosa é, de um lado, a expressão da miséria real e, de outro, o protesto contra ela. A religião é o soluço da criatura oprimida, o coração de um mundo sem coração, o espírito de uma situação carente de espírito. É o ópio do povo. (MARX, 1979a, p. 94).

Para Marx, portanto, a religião seria apenas um sintoma e um epifenômeno - a expressão do sofrimento humano, na tentativa de superar o sofrimento sem, todavia, ação concreta de transformação das condições em que se dá o sofrimento. Não seria a “doença” em si, mas seu sintoma. Quando a condição material e concreta, objetiva e histórica da humanidade transformar-se, isto é, quando o homem desalienar-se histórica e politicamente, a religião, sintoma que é, desaparecerá, porque

a verdadeira felicidade do povo implica que a religião seja suprimida, enquanto felicidade ilusória do povo. A exigência de abandonar as ilusões sobre sua condição é a exigência de abandonar uma condição que necessita de ilusões. Por conseguinte, a crítica da religião é o germe da critica do vale de lágrimas que a religião envolve numa auréola de santidade. (MARX, 1979a, p. 94).

No projeto revolucionário que elabora, Marx é um Feuerbach que se lança à ação de transformação da realidade. Nisso, Marx o ultrapassa, mas sem deixar de, ao mesmo tempo, trilhar o caminho discernido pelo filósofo. Nenhuma contradição fundamental entre as duas teorias. 
Aqui caberia a pergunta pela possibilidade de aliança entre determinada expressão histórica de religião e o marxismo. O contexto remete, por exemplo, à última entrevista de Paulo Freire, na qual ele declara que, "movido por certa lealdade ao Cristo”, “os mangues” de Recife despertaram nele a insuficiência de Jesus Cristo para a transformação concreta daquela realidade. Nesse momento, ele declara, recorreu a Marx, como seu camarada, permanecendo até o momento da entrevista, 17 de abril de 1997, caminhando com quem ele chama igualmente de camarada, tanto Jesus Cristo quanto Marx. Nas suas palavras, com este, na mundanidade, e com aquele, na transcendentalidade ${ }^{8}$. Se, como se verá adiante, uma teoria reducionista da religião a toma como instrumento de manutenção da ordem social, dá-se nesse sentido, na comparação da compreensão freireana de sua experiência religiosa com o projeto voltairiano, a curiosa situação de duas proposições radicalmente contrárias sobre a religião - num caso, a transformação das condições materiais a partir da religião e, noutra, justamente a manutenção dessas condições.

\subsection{Religião como neurose}

Freud procurou analisar a religião em perspectiva psicológica, o que justifica o fato de Pals (2006, p. 295-296) o ter classificado, a seu modo, nas teorias de religião marcadas pela “orientação psicológica”. Um pouco de abordagem "histórica", um pouco de abordagem psicológica e um pouco de abordagem social, tentou elaborar uma "teoria da religião" à luz da compreensão do fenômeno religioso de sua época, bem como de teorias anteriores. Trata-se de uma teoria reducionista da religião, de sorte que, conquanto de “orientação psicológica”, a teoria de Freud consideraria que "is certain that religious beliefs are erroneous" (PALS, 2006, p. 64), ainda que por meio delas se possam investigar "important questions about human nature" (PALS, 2006, p. 64).

\footnotetext{
${ }^{8}$ A entrevista encontra-se disponível em duas partes: Ultima Entrevista a Paulo Freire $1^{\circ}$ parte (Ultima Entrevista a Paulo Freire $1^{\circ}$ parte: https://www.youtube.com/watch?v=Ul9OheSRYfE) e Paulo Freire Ultima Entrevista $2^{\circ}$ parte (https://www.youtube.com/watch?v=fBXFV4Jx6Y8).
} 
Em "Totem e tabu", tateando no escuro das especulações "históricas" e em íntima associação com concepções coetâneas sobre a religião e a evolução da espécie humana (PALS, 2006, p. 65-69), Freud desenvolveu a "teoria" de que, nos primórdios da espécie, os homens teriam assassinado o "pai” da horda tribal. O parricídio se teria deslocado para níveis cada vez mais profundos da mente humana, de sorte a converter-se numa espécie de constante antropológica, responsável, em última análise, pela pulsão religiosa da espécie: “o pai morto tornou-se mais forte do que o fora vivo" (FREUD, 1996, p. 146).

A esse "mito" histórico-fundante, corresponderia, de outro lado, o desamparo do homem primitivo, que experimenta a sua consciência de viver na "natureza" com a percepção de desproteção e abandono. Nessa condição, o homem - tanto o primitivo quanto os seus descendentes, incluindo o Homo sapiens experimentaria medo e angústia. É o medo e a angústia que disparariam aquele mecanismo já descrito por Feuerbach - a projeção antropológica.

O que "se compreende, se levarmos em consideração o fato de que toda a sua interpretação psicogenética da religião se fundamenta no 'complexo paternal' resultante da morte do Pai primitivo, e que, para ele, a religião, na sua natureza, é uma ilusão” (MACIEL; ROCHA, 2008, p. 747), em “Os atos obsessivos e as práticas religiosas", Freud vincularia diretamente a religião à neurose. Nesse trabalho inscrevem-se as perspectivas mítico-históricas de “Totem e tabu”, mas, agora, historicizando o sintoma e circunscrevendo-o à infância e às reinscrições psicanalíticas da relação entre o pai e a criança. O paralelo permanece: pai versus horda tribal e pai versus criança. Para Freud, a religião está relacionada diretamente a mecanismos de neurose obsessiva latentes na espécie humana e expressas desde tão cedo quanto a infância. Funcionando até certo ponto como uma espécie de terapia, transferindo para a coletividade o que poderia se expressar subjetivamente, já que, por caracterizar-se a religião pela faculdade de manter as pessoas “num estado de infantilismo psicológico e arrastá-las a um delírio de 
massa, ela consegue poupar a muitos uma neurose individual” (FREUD, 2006, p. 92), porque "os devotos acabam por se salvaguardar do risco de certas enfermidades neuróticas" (DAVID, 2003, p. 37). Nesse sentido "terapêutico", podese aproximar o que se tem afirmado sobre a tese de Freud a respeito da religião e a famosa declaração de Lacan. Para Freud, a "religião é uma ilusão, não necessariamente porque seja errada, mas porque leva o homem a evitar a dura realidade de suas próprias limitações humanas” (ROSA, 1992, p. 26). Para Lacan, “a religião é feita para isso, para curar os homens, isto é, para que não percebam o que não funciona” (LACAN, 2005, p.72).Nesse caso, a religião funcionaria como uma "muleta" de segurança psicológica para o homem - de tal forma que, se não houvesse a religião, o homem buscaria outras formas de produzir segurança psicológica. Não apenas o homem tomado individualmente, mas a própria sociedade como um todo se utiliza da religião como forma de garantir os contratos sociais.

\subsection{Religião como sistema controle social}

Apesar de que se tenha dito que "Voltaire não sabia bem o que pensava em matéria de religião" (LEPAPE, 1995, p. 77), o fato é que, em "Deus e os homens", o famoso iluminista deixou registrado um verdadeiro programa de instrumentalização da religião, a partir do qual se pode depreender, de modo relativamente fácil, a "quase teoria" que lhe subjaz. "Deus nos preserve de banir o culto público!", ele disse (VOLTAIRE, 1995, p. 180). E acrescenta: “ousaram acusar-nos de querer isso: é uma impostura atroz" (VOLTAIRE, 1995, p. 180). Bem, se seus acusadores estavam certos ou não quanto ao que Voltaire houvesse querido até aquele momento, o fato é que, na sequência, desenha-se claramente um programa de instrumentalização político-social da religião, e uma crítica, nesse contexto, da religião tal qual praticada. Voltaire começa por dizer que "nenhuma sociedade pode subsistir sem justiça” (VOLTAIRE, 1995, p. 182), de cuja máxima extrai, então, a seguinte conclusão: “preguemos então um Deus justo” (VOLTAIRE, 1995, p. 182). Que relação há entre uma coisa e outra? É que "se a lei do Estado pune os crimes conhecidos, anunciemos, pois, um Deus que pune os crimes 
desconhecidos" (VOLTAIRE, 1995, p. 182), pois "que outro freio podia, pois, ser posto a cupidez, às transgressões secretas e impunes, além da ideia de um senhor eterno que nos vê e que julgará até mesmo nossos pensamentos mais íntimos?” (VOLTAIRE, 1995, p. 5). Para Voltaire, a função da religião é, portanto, garantir a ordem social, operando por meio de um sistema ameaçador de crenças, cujo objetivo seria a contenção do crime: a polícia age nas ruas; a religião, nas consciências. O Estado deve portar-se de forma publicamente religiosa, de sorte que, de um lado, “o homem de Estado seja teísta” (VOLTAIRE, 1995, p. 182), e, de outro, que "a lei do Estado comande a religião" (VOLTAIRE, 1995, p. 183). A religião deve constituir instrumento do Estado, com o objetivo precípuo de manutenção da ordem social.

Voltaire vê na religião tal qual praticada em seus dias - e ele se refere explicitamente aos cristianismos em voga - um risco severo para a sociedade. É que, a despeito de os religiosos dizerem "uma coisa provável e necessária ao gênero humano" (VOLTAIRE, 1995, p. 182), ao mesmo tempo desfiguram o instrumento "mediante fábulas absurdas" (VOLTAIRE, 1995, p. 182). A religião deve ser expurgada de tais fábulas (basicamente, a mitologia bíblica e conciliar9), cuja invenção constituiria "velhacaria” (VOLTAIRE, 1995, p. 183). Em favor de quê? "Pôr um Deus poderoso e justo no lugar dessas espantosas farsas, extrema sabedoria” (VOLTAIRE, 1995, p. 183). Seu programa não podia ser mais claro:

Queremos um culto puro. Começamos faz dois séculos e meio a limpar os templos [...] tiramos deles as teias de aranha, os trapos apodrecidos, os ossos dos mortos, que Roma nos enviara para infectar as nações. Concluamos tão nobre obra. Sim, nós queremos uma religião simples, sábia, augusta, menos indigna de Deus e mais feita para nós: numa palavra, queremos servir a Deus e aos homens. (VOLTAIRE, 1995, p. 180181, grifos do autor).

\footnotetext{
9 Voltaire não está se referindo a invenções populares, mas a temas fundamentais da doutrina cristã e do conteúdo das Escrituras: "Quem ousar dizer 'Deus me falou' é criminoso" (VOLTAIRE, 1995, p. 182); “Deus passear! Deus falar! Deus escrever numa colina! Deus combater! Deus tornar-se homem! Deus-homem morrer pelo último suplício!" (VOLTAIRE, 1995, p. 183). Seu programa é de uma religião moral e racional, purgada, portando, dos elementos mitológico-doutrinários clássicos dos cristianismos históricos ("sua lei está no coração de todos os seres razoáveis, e não em outra parte"). (VOLTAIRE, 1995, p. 183). Há quem interprete o conjunto de elementos acima na mesma direção, mas de modo ainda mais acentuado: "Voltaire pretende uma reforma cosmopolita que substitua as religiões institucionais, fundadas em dogmas particulares, pela 'religião natural' em conformidade com a razão" (MOTA, 2014, p. 96).
} 
O receio que Voltaire antecipa ocuparia a cabeça dos clérigos: "mas, se meu povo raciocinar, ele se erguerá contra mim" (VOLTAIRE, 1995, p. 183). E, como que medindo a povo a partir do ideal da racionalidade iluminista, Voltaire contraargumenta que "você se engana: quanto menos fanático ele for, mais fiel" (VOLTAIRE, 1995, p. 183). Voltaire considera que os dogmas, isto é, aquele conjunto de farsas que somente tomado por "extrema tolice" nelas se pode crer (VOLTAIRE, 1995, p. 183), são obstáculos à religião da razão, instrumento imprescindível do controle dos homens:

qual a menos ruim de todas as religiões? Aquela em que se veem menos dogmas e mais virtudes [...]. O dogma fez morrer nos tormentos dez milhões de cristãos. A moral não teria produzido sequer um arranhão. $\mathrm{O}$ dogma leva, além disso, a divisão, o ódio, a atrocidade, às províncias, às cidades, às famílias. (VOLTAIRE, 1995, p. 183-184).

Para quem foi tomado como alguém que "não sabia bem o que pensava em matéria de religião", Voltaire tinha muito a dizer (cf. ARKUSH, 1993, p. 223-243). A rigor, com as devidas adaptações teístas, tal projeto guarda certa dose de atualidade, podendo ser identificado, por exemplo, naqueles discursos que assentam o Ensino Religioso Escolar no fundamento da moralização infantil. No contexto da violência social e escolar, sugere-se que o Ensino Religioso Escolar constitua vetor de "educação de valores": "identificamos como um dos protagonistas na construção da paz o próprio ER como espaço privilegiado de construção de experiências” (BECKER, 2010, p. 107). Para Voltaire, a religião fertilizaria os impulsos de moral e justiça entre os homens da sociedade. Para Becker, a religião fertilizaria valores no coração das crianças.

\subsection{Religião como projeção social}

Aaron (2002, p. 520) disse que "Durkheim diz que a sociedade é criadora de religião", e Eliade (1989, p. 30) declarou que, "para Durkheim, a religião era uma projeção da experiência social”. Provavelmente, pretende-se que com tais afirmações se pudesse traduzir a declaração do próprio Durkheim (1915, p. 419): "the Idea of society is the soul of religion". Para Vásquez (2011, p. 128), a questão do fundamento social da religião se prenderia ao fato de "que Durkheim desenvolve 
uma forte versão de construtivismo social [...] que traça a origem das categorias de percepção a priori não de Deus ou de estruturas do cérebro, mas da sociedade”. Eliade acrescenta que os estudos com povos australianos levados a termo pelo sociólogo teriam-no levado a concluir que “o sagrado (ou 'Deus') e o grupo social são uma e a mesma coisa” (ELIADE, 1989, p. 30). Nesse sentido, Eliade classifica a teoria durkheimiana como reducionista (ELIADE, 1989, p. 35), Vásquez (2011, p. 216-217), como funcionalista e Pals (2006, p. 13) como sociofuncionalista.

Deve-se ter em mente que Durkheim igualmente declarava que "a distinção entre sagrado e profano é [...] central em todas as religiões” (VÁSQUEZ, 2011, p. 127; cf. PALS, 2006, p. 13), considerando-a uma categoria universal (VÁSQUEZ, 2011, p. 263; GUTRIE, 1993, p. 203). Para Durkheim (1965, p. 261) “a força religiosa é somente um sentimento inspirado pelo grupo em seus membros”, sendo por ele projetada e objetificada. A sacralidade assumida pelos objetos na experiência religiosa constituem propriedades “adicionadas a eles" (DURKHEIM, 1965, p. 261). Sendo assim, é de se observar que uma das principais categorias de aproximação à religião utilizadas por Eliade - o sagrado - já se encontrava assentada em Durkheim, não sendo suficiente, todavia, para produzir neste a convicção da independência eidética da religião em face da cultura, que acompanha as pesquisas do fenomenólogo.

Há tanta distinção quanto semelhança entre Durkheim, de um lado, e, de outro, ao mesmo tempo Feuerbach e Marx. Com Feuerbach, a distinção se dá pelo fato de que, em um, trata-se de projeção subjetiva, ao passo que, para o outro, a religião constitui projeção, sim, mas social (GUTRIE, 1993, p. 67). Quanto a Marx, Vásquez expressou de modo suficientemente conciso a distinção: "o segredo da religião está [...] nas dinâmicas da solidariedade social (Durkheim) ou conflito econômico (Marx)” (VÁSQUEZ, 2011, p. 170-171). A semelhança entre os dois teóricos, naturalmente, advém justamente do assentamento da religião na sociedade como um todo. 


\subsection{Religião como sistema sociocultural}

A classificação da compreensão weberiana da religião, que a toma como "sistema cultural", é aqui apropriada de Vásquez (2011, p. 218): "position [...] advocated by Max Weber [...] a precursor to 'Religion as a Cultural System'”. A avaliação de Pals (2006, p. 165) de ser "The Sociology of Religion" de Weber menos a apresentação de uma tese do que a exploração dos temas relacionados à religião parece confirmar-se em outra obra weberiana aplicada à religião (WEBER, 1958), na qual o teórico explora a religião da Índia. Parece que aqui se toca naquela questão apontada por Negrão (2005, p. 25): a "questão da essência e da origem do fenômeno religioso fora por Weber afastada como sociologicamente irrelevante ou inoportuna, já no início de suas análises sobre a comunidade religiosa”, de sorte que lhe interessaria basicamente descrever, e não propriamente definir. Nesse caso, as asserções mais propriamente teóricas precisam ser recolhidas dos relatórios de exploração weberianos. Nesse sentido, Vásquez (2011, p. 219) sente-se autorizado a assim sintetizar as proposições de Weber em seu "The Sociology of Religion": "Weber seems to be saying: tell me what your life conditions are and I will tell you the extent to which your religion is rationalized". Talvez para isso também aponte a forma como Pierucci (2006, p. 121) referiu-se a "momentos" de Weber:

É um momento weberiano magnífico, insólito (para não dizer insolente) por sua crueza sociológica de 'especialista sem coração', já que fala da religião desfazendo laços de família, laços de sangue que a todos nós se afiguram de alguma forma sagrados. (PIERUCCI, 2006, p. 121).

No entanto, talvez se pudesse acrescentar ao conjunto das observações acima o comentário do mesmo Pierucci (2006, p. 123), segundo o qual o interesse de Weber diferiria fundamentalmente do de Durkheim, uma vez que estaria voltado a "identificar a dinâmica própria, e propriamente religiosa, daquela fraternidade nova de seguidores que, no limite do tipo ideal, vai resultar na formação de seitas”. Ou seja, trata-se da criação social da religião, mas de um tipo que recorta a comunidade de seu contexto social mais amplo e a circunscreve em uma nova dinâmica restrita e específica (PIERUCCI, 2006, p. 122-123). Enquanto o interesse de Durkheim seria o de pensar a religião em termos gerais e sua relação 
genética com a sociedade em geral, Weber teria diante dos olhos apenas comunidades socialmente criadas por mecanismos de ruptura de laços sociais anteriores - seitas (PIERUCCI, 2006, p. 122). Dado, portanto, que "a religião é uma 'ação comunitária”' (OLIVEIRA, 2009, p. 137), a distinção weberiana dar-se-ia em precisar que a religião é “um determinado tipo de ação comunitária” (WEBER, 2000, p. 279).

Se Vásquez está correto em classificar a teoria weberiana como a proposição da religião como sistema cultural, e dado que Pals inclui tanto Weber quanto Geertz em sua rubrica “orientações humanistas”, nesse caso pode-se ou deve-se imediatamente acrescentar ao campo teórico em análise a tese de Geertz, tornada explícita pelo próprio:

Religião é (1) um sistema de símbolos que atua para (2) estabelecer poderosas, penetrantes e duradouras disposições e motivações nos homens através da (3) formulação de conceitos de uma ordem de existência geral e (4) vestindo essas concepções com tal aura de fatualidade que (5) as disposições e motivações parecem singularmente realistas. (GEERTZ, 2008, p. 67).

Para Geertz, a religião cumpre uma função social, devendo "servir, tanto para o indivíduo como para um grupo" (GEERTZ, 2008, p. 90). A partir de suas funções culturais - a saber, modelo $d a$ atitude e modelo para a atitude (grifos de Geertz) - estabelecem-se, em decorrência, as funções sociais e psicológicas da religião (GEERTZ, 2008, p. 90).

\subsection{Religião como violência}

“A religião é intrinsecamente violenta", com grifo no original, é a conclusão a que chega o autor de artigo publicado há uma década (LUZ, 2008, p. 276), no qual avalia o fenômeno religioso em relação ao tema da violência. De um lado, avaliou-se a correlação entre religião e violência a partir de duas vertentes. Primeiro, analisando-se as diferentes formas e expressões da violência religiosa: auto violência, violência psicológica, verbal, cultural, política, social, física, sexual, ambiental, simbólica e contra as minorias (LUZ, 2008, p. 268-271), e, em seguida, 
classificando os conflitos religiosos em termos de suas dimensões e expressões: megaconflitos, macroconflitos, miniconflitos e microconflitos religiosos (LUZ, 2008, p. 271-272). De outro lado, desenvolveu a avaliação quanto ao "problema dos livros sagrados”, apresentado nos seguintes termos:

Os textos sagrados [...] apresentam um grave problema: estão repletos de apelos à violência descritos em linguagem ambivalente. A ambiguidade da linguagem religiosa reside no fato de um mesmo texto servir tanto a interpretações intolerantes, geradoras de cruel fanatismo, quanto a interpretações condescendentes, inspiradoras de movimentos pacifistas. Esta ambiguidade torna-se letal no momento em que os religiosos atribuem a autoria do texto aos seus respectivos deuses ou divindades. (LUZ, 2008, p. 272).

A despeito das ressalvas que o autor faz quanto a se poder eventualmente contornar o espírito violento inerente à religião e, particularmente, aos textos sagrados, a tese defendida é a de que, a rigor, "os textos violentos conduziram e continuam a conduzir indivíduos e grupos a protagonizarem todo tipo de tragédia” de forma que "acentuar os trechos pacíficos desses livros não apagará a presença de outros tantos inspiradores de segregação, ódio e carnificina” (LUZ, 2008, p. 274).

Deve-se ressalvar que, na prática, o artigo concentrou-se sobre três religiões: Judaísmo, Cristianismo e Islamismo. Por força disso, talvez se pudesse considerar que, na verdade, o artigo tem em mira os monoteísmos globais, de sorte que a eventual validade da tese de que a religião constituiria processo intrinsecamente violento (o que aqui não se avalia) se aplicasse restritivamente àquelas expressões religiosas, mas não necessariamente a todas as demais. De qualquer maneira, teorias da religião como animismo, por exemplo, não se aplicam a todas, e, todavia, estão presentes em praticamente todos os manuais disciplinares disponíveis, de sorte que a eventual validade parcial da tese em questão não imporia sua exclusão do rol das teorias analisadas.

De qualquer forma, o tema da relação entre religião e violência é amplamente tratado na literatura. Em 2003, em um manual publicado pela Cambrigde University Press, assentava-se tese relativamente próxima à mencionada. A potencial violência religiosa responderia majoritariamente ("for the 
most part") a "um conjunto bastante restrito de interesses substantivos específicos" ("a rather narrow set of specifiable substantive interests") (HALL, 2003, p. 380)10. Não se afirma que a religião seja intrinsecamente violenta, mas de que, em razão de certos interesses, a potência violenta das religiões frequentemente se atualiza.

De qualquer forma, o citado Hall (2003, p. 380) considera que (a) a relação complexa entre religião e violência, (b) a variedade de aproximações teóricometodológicas, bem como valorativas, à pesquisa do tema e (c) o caráter limítrofe da violência religiosa têm contribuído para o cenário investigativo, do qual conclui: "the study of violence and religion has been strikingly uneven" (HALL, 2003, p. 280). A despeito de, nas palavras de Hall (2003, p. 380), haver "muitos bons estudos de caso, bem como importantes investigações comparativas e gerais”, nossa compreensão dos processos sociais que envolvem religião e violência permanece rudimentar. Registre-se que em 2019, Wright e Khoo (2019, p. 1-28) publicaram um relatório que procurava delinear os casos de aproximações empíricas ao fenômeno de imbricação entre religião e violência, indicando uma relativamente extensa bibliografia sobre o tema. A citada publicação pode ser vinculada ao item (c) das considerações de Hall, mencionadas no parágrafo anterior, quando se indicava o caráter limítrofe da violência religiosa. No entendimento de Wright e Khoo (2019, p. 17), "in cases where aspects of religion are associated with aggression and violence, these aspects have direct secular counterparts and cannot be said to be unique features of religion”. Estaria aí ressalvada a origem propriamente não religiosa da violência religiosa. No entanto, outra declaração, dessa vez de Brubaker (2015, p. 12), dá conta exatamente do contrário: "religion does provide a potent assemblage of moral, ideological, and organizational resources that can, in certain contexts, inform, legitimate, or sustain violent conflict”. Considerando que Brubaker analisa apenas os conflitos políticos, há de se considerar que o mesmo poderia ser dito quanto à relação entre religião e

\footnotetext{
${ }^{10} \mathrm{O}$ conjunto de interesses seria o seguinte: "maintenance and expansion of religious commitment (through social control, conversions, competition with other religious organizations, colonial expansion, and repression of deviant movements); affirmation of religious beliefs through culturally normative (routine) practices of violence; struggles for independence from the regime of an established social order by nationalist, anticolonial, or other countercultural movements; and, countercultural martyrdom under conditions of apocalyptic war, 'persecution' and/or defeat" (HALL, 2003, p. 380). Salvo engano, rubricas em relação às quais uma série considerável de práticas violentas poderia ser mencionada.
} 
os demais tipos de violência, por exemplo, analisados por Luz (2008, p. 267-277) e mencionados no início da presente discussão. Seja como for, constituiria procedimento de ocultamento da realidade analisar o fenômeno religioso sem levar em consideração sua altamente expressiva carga de violência intrínseca, tanto simbólica quanto em todas as demais especificações que se queiram dar ao termo violência.

\subsection{Religião como texto}

Mesmo que se assuma que "símbolo é sempre um texto" (SOUZA, 2015, p. 76) e que se tenha em mente que uma imagem pode ser tratada como um símbolo (SHELESTIUK, 2003, p. 233-259), de sorte que se possa assim transitar semioticamente entre os termos imagem e texto, no auge da era das imagens, quando se pode falar de uma "cultura das imagens" (MIRANDA, 2007, p. 34-35), não deixa de ser curioso o emprego do termo "texto" na formulação da proposta de assumir-se a religião como texto (NOGUEIRA, 2012, p. 13-20). Nos termos da proposta, seria necessário tratar a religião como texto "para analisar a religião como um sistema de comunicação e elaboração de mensagens" (NOGUEIRA, 2012, p. 16-17). Passo seguinte, então, seria substituir os termos “expressão religiosa" por “texto da religião” (NOGUEIRA, 2012, p. 17). A justificativa para o procedimento é a forma como se encara a religião - sistema de comunicação -, e o conceito de texto que se utiliza é declarado como tributário da "semiótica da cultura de Iúri Lotman” (NOGUEIRA, 2012, p. 17; cf. AMÉRICO, 2015, p. 123-140)¹1. Texto, então, seria uma "unidade de sentido", desdobrando-se de seu uso (sim, uso, porque "o consumidor não decifra o texto, mas trata, entra em contato com ele" (NOGUEIRA, 2012, p. 19) não somente a geração de novos significados, mas a condensação da memória cultural (NOGUEIRA, 2012, p. 18). Na forma de conclusão do raciocínio, Nogueira (2012, p. 20) propõe: “nossa hipótese é a de que o texto da religião, dado seu caráter altamente semiotizado, possui um alto grau de

\footnotetext{
${ }^{11}$ No capítulo "Text and ritual: the meaing of the media for the History of Religion (ASMANN, 2006, p. 122-138), basicamente se acionam os conceitos descritos. Por exemplo: "por 'textos culturais' nós compreendemos (..) não apenas textos, mas também danças, ritos, símbolos, e o resto, que possuam autoridade normativa formativa para estabelecer significados e identidade" (ASMANN, 2006, p. 123). Quatro anos antes, em uma entrevista, Geertz teria dito: “I've read the cockfight as a text. Now that's an action, and I textualize it perhaps, but l've tried to look at it as a Balinese text" (PANOURGIÁ, 2002, p. 427).
} 
poliglotismo". Dada "a dinamicidade dos textos religiosos e das transformações desses na semiosfera requer[-se] essa perspectiva de análise” (NOGUEIRA, 2015, p. 122), isto é, na ótica da semiótica da cultura. Nesse caso, o acontecimento histórico a que está submetido um texto da religião "fica a cargo das preferências do intérprete" (NOGUEIRA, 2012, p. 28).

\section{Teorias não reducionistas da religião}

Um fato religioso "puro" é coisa que não existe.

(ELIADE, 1989).

Das cinco teorias abaixo descritas, quatro delas (animismo, mana préanimista, magia e urmonoteísmo) podem ser situadas contextualmente naquilo que Eliade chama de “a obsessão das origens” (ELIADE, 1989, p. 62). Não pretendem tanto dizer o que uma religião é, mas como ela surgiu e em que então consistiu, ainda que aspectos constitutivos de algumas delas permaneçam discerníveis em religiões contemporâneas - por exemplo, o Xintoísmo é uma religião animista (SANDVIK, 2011, p. 31-39). A quinta teoria analisada é a diretamente relacionada a Eliade, que aqui se classifica como não reducionista por não se tratar de um artigo de avaliação crítica e, na literatura, ser a teoria eliadiana assim tratada.

\subsection{Religião e animismo}

Já referido como "um dos mais antigos conceitos antropológicos, se não o primeiro" (BIRD-DAVID, 1999, p. 67), em 1871 Tylor publicava "Primitive Culture", em que descrevia o que considerava então a forma "primitiva” da religião - o animismo, tese que, segundo Eliade (1989, p. 28), teria deixado de ser universalmente aceita já no início do século XX. Tylor tratava como animismo, "uma das grandes doutrinas religiosas da humanidade” (TYLOR, 1871, p. 1), o conjunto das crenças humanas primitivas, na quais se assumiam a existência de "almas" ("souls, spirits, ghosts or phantoms") que sobreviviam à morte e à degradação. Dessa forma, então, Tylor explicava a religião: o homem primitivo relacionou-se com todas as coisas como se fossem "vivas" em sentido profundo, 
como se todas fossem dotadas de uma alma inteligente, intencional, relacional, porque, segundo sua compreensão, a religião primitiva aplicava aquelas ideias tanto a pessoas, quanto a "lower animals, plants and things" (TYLOR, 1871, p. 1). Trata-se, nas palavras de Harris (1983, p. 186) da "crença quanto a haver dentro dos corpos visíveis e tangíveis, uma alma, normalmente invisível, normalmente intangível”, a partir de cujo núcleo comum "cada cultura elabora seu próprio conceito de alma” (cf. BROWN; WALKER, 2008, p. 297-299). Convém, no entanto, deixar acentuado o fato de que, para Tylor, a questão não era tanto a crença em "almas" quanto a crença em sua sobrevivência após a morte, "as especulações filosóficas do homem primitivo a respeito da imortalidade" (VÁSQUEZ, 2011, p. 233), questão derivada também do fato de os seres humanos primitivos interpretarem a presença daqueles seres animados e "inanimados" nos sonhos como a prova de sua sobrevivência para além do mundo dos vivos (TYLOR, 1871, p. 1-2).

Uma teoria que se elabora em relação ao conteúdo positivo da crença religiosa e que não "reduz" a religião a algum componente especificamente não religioso, o "animismo" nunca foi unanimemente aceito como "a” teoria da religião, sendo inclusive confrontada em sua defesa de constituir o estágio mais antigo da crença religiosa (ELIADE, 1989, p. 28), mas fez relativo sucesso no último quarto do século XIX e, especialmente, na sua virada para o XX e sua primeira década. No entanto, concentrando-se fundamentalmente no tema da "animação" de objetos considerados inanimados pela cultura moderna, pesquisas relativamente recentes têm recuperado ou desenvolvido aproximações multidisciplinares ao tema do animismo, recolocando-o na agenda das pesquisas (BROWN; WALKER, 2008, p. 297-299; CASTRO, 2004, p. 463-484).

\subsection{Religião e mana pré-animista}

Como reação à tese animista, em 1900, Marett (1900, p. 162-184) publicou na revista "Folklore" um artigo chamado "Pre-animist religion", em que deixava subentendido que o "animismo" constitui, na verdade, um desdobramento 
“racionalizador” de um estágio anterior da religião - nesse caso, um estágio préanimista, “a certain very primitive phase of Religion” (MARETT, 1900, p. 162).

Marett defendeu a tese de que o estágio original da religião não compreendia as coisas como portadoras de almas "pessoais" e individuais, característica do animismo, mas se baseava na percepção de uma força impessoal que impregnava tudo e todos e que causava uma sensação de "pasmo e espanto" nos homens (ELIADE, 1989, p. 28-29; BENGTSON, 1979, p. 645-659). A essa "força impessoal", Marett deu o nome de mana.

Outra das teorias que procuram sistematizar a religião a partir de seu conteúdo experiencial positivo, sem sua redução eidética a elementos não religiosos da experiência cultural, a teoria de mana logrou sucesso e foi reconhecida como válida para a descrição da crença de vários povos, sob a forma de outros designativos correlatos - orenda (iroqueses) e wakan (sioux), em tribos autóctones (e iroqueses) dos Estados Unidos da América; manngur, entre os aborígenes australianos; baraka, entre tribos do norte da África e hasina, entre habitantes de Madagascar (WINTHROP, 1991, p. 171-172).

\subsection{Religião e magia}

Outra teoria da religião, também distinta do animismo, constitui a tese de Frazer, publicada em "The golden bough", obra inicialmente em dois (1890) e três volumes (1900), e aumentada para 12 volumes em sua terceira edição, publicada entre 1906 e 1915 (ELIADE, 1989, p. 29). Para Frazer, a magia seria um estágio mais antigo do que a religião, dela derivando todos os demais estágios de sua constituição (ELIADE, 1989, p. 31).

A recepção da obra de Frazer é marcada por profunda ambiguidade. De um lado, é convidado por aquele a quem tratará in loco como amigo a prefaciar seu “Argonautas do Pacífico Ocidental” (MALINOWSKI, 1978, p. 5-9), no qual Frazer não deixa de observar a forma como Malinoski assentou "esse predomínio conspícuo da magia sobre a religião”. De outro lado, o filósofo Wittgenstein teria 
declarado: "Frazer é muito mais selvagem do que a maioria desses selvagens" (NIELI, 1987, p. 175). Agradando ou desagradando os especialistas, com a tese de constituir a magia estágio ainda mais anterior do que o pré-animismo marettiano está-se, mais uma vez, diante de uma elaboração teórica a partir do conteúdo positivo da experiência religiosa, e não de sua redução a aspectos mais propriamente extra religiosos da cultura.

\subsection{Monoteísmo original versus politeísmo original}

Segundo Eliade (1989, p. 30), cada qual a seu tempo e modo, as teses a respeito do animismo, do mana e da magia teriam agrado um grande número de teóricos. "O único que rejeitou todas as teorias vastamente aclamadas de seu tempo" (ELIADE, 1989, p. 30) foi Schmidt, autor que defendeu a tese de um monoteísmo original como a base para a origem da religião (ANTONOV, 2018, p. 1). Em termos de teoria, poder-se-ia dizer que a religião constitui o desdobramento, em termos de manutenção ou perversão, da crença monoteísta original. Segundo Araújo (2013, p. 32), para Schmidt, "todos os povos, por mais primitivos que fossem, teriam um substrato religioso monoteísta”.

É uma tese radicalmente contrária à de Hume (2004, p. 24-28), que afirmava que a humanidade era originalmente politeísta. Isso já em 1757, data de publicação de seu "The natural history of religion". Nas palavras de Hume, "o politeísmo ou a idolatria foi [...] a primeira religião da humanidade" (HUME, 2004, p. 23). Para um esforço de compreensão da defesa de uma tese diametralmente oposta a outra, anterior à sua, o fato de Schmidt ter sido ordenado sacerdote católico em 1892 não deixa de ser sugestivo (ARAÚJO, 2013, p. 30-49). Schmidt defende que, no início, a "revelação primitiva" do "Deus único" constituía patrimônio humano, característico das culturas primárias. Segundo Araújo (2013, p. 31), nas formulações de Schmidt, tais “culturas primárias seriam monoteístas e organizadas a partir da religião, da família nuclear, da monogamia permanente e de um código moral exemplar”. O surgimento histórico de culturas secundárias teria degradado a condição original da religião: "Schmidt não partilhava dos 
princípios evolucionistas da época, mas advogava a tese de que, em decorrência de um processo de degeneração, as culturas teriam deixado de ser monoteístas, monogâmicas etc.” (ARAÚJO, 2013, p. 31). Se, para Hume, a humanidade transita do politeísmo para o monoteísmo, para Schmidt é o contrário, a deterioração do monoteísmo original é que produziu o politeísmo.

\subsection{Sagrado e sentido}

Tem-se considerado um capítulo das teorias "substantivas" - não reducionistas - da religião as teses elaboradas no ambiente da História das Religiões e da Fenomenologia da Religião, em cujo cenário destaca-se Eliade, que, segundo Pals (2006, p. 194) "developed his ideas in direct opposition to reductionist theories, which in his view seriously misunderstood the role of religion in human life". De outro lado, "Mircea Eliade approach to religion has been described as (among other things) essencialist, ahistorical, theological, etc.” (STUDSTILL, 2000, p. 177).

Pode constituir, todavia, uma operação classificatória equivocada - ao menos, ambígua. Teórico-metodologicamente falando, é verdade que a Fenomenologia da Religião aproxima-se de seu objeto de estudo sem efetuar "juízo [crítico] de valor", aplicando a "suspensão de juízo" característica da escola fenomenológica. Todavia, a suspensão teórico-metodológica de juízo não significa, necessariamente, a adesão epistemológica ao conteúdo propositivo do objeto de estudo - emprega-se o discurso religioso para a compreensão do que ele diz de si mesmo, mas, ao final do processo, labora-se uma teoria que, em si, não guarda equivalência de nível com o discurso da própria religião, antes, constitui uma leitura científico-humanista dela (ELIADE, 1989, p. 15-25).

Seja como for, para uma "introdução" ao tema, mantém-se a escola fenomenológico-religiosa (a rigor - histórico-fenomenológico-religiosa!) na seção não reducionista. Segundo essa escola, o "sentido" da religião - e do "sagrado" deve ser apreendido do próprio fenômeno religioso (ELIADE, 1990, p. 23-63). 
Nesse caso, devem-se recolher - da história das religiões - tantos casos (documentos) quanto possível (ELIADE, 1989, p. 22-23; 1990, p. 23-24); deve-se analisar cada um desses casos e deve-se construir um sistema de classificação, dentro de cujos conjuntos se podem alocar modalidades equivalentes de "religião" e “sagrado", de sorte a constituir-se um sistema com base histórico-material para a compreensão do fenômeno religioso (ELIADE, 1989, p. 23, nota 7).

Isso no campo teórico-metodológico. Quanto à "tese” de fundo, a escola fenomenológica tende a apresentar a religião como um sistema de sentido para a vida, sentido que emerge da experiência universal do "sagrado", experiência que se estabelece em relação indissociável com seu oposto - o profano. Nesse sentido, o sagrado e o profano seriam as duas faces contrárias e necessárias da experiência religiosa, de tal sorte que, a partir da sua expressão na cultura e na sociedade, o ser humano encontra seu lugar e seu campo de orientação no cosmo (ELIADE, 1990, p. 36-38).

Dois elementos teórico-metodológicos das operações heurísticas propostas por Eliade devem incidir sobre a avaliação crítica que se deve fazer quanto a classificar sua proposta como não reducionista ou reducionista. O primeiro elemento é sua própria proposição teórico-metodológica, que se poderia sintetizar por meio de suas próprias palavras:

Um dado religioso revela seu sentido mais profundo quando é considerado no seu plano de referência e não quando é reduzido a um dos seus aspectos secundários ou aos seus contextos [...]. Isto não significa, evidentemente, que um fenômeno religioso possa ser compreendido fora de sua 'história', isto é, fora dos seus contextos culturais e socioeconômicos. Um dado religioso 'puro', fora da história, é coisa que não existe, pois não existe um dado humano que não seja ao mesmo tempo um dado histórico. (ELIADE, 1989, p. 20-22).

Parece que, em relação às abordagens reducionistas, a de Eliade apenas se deteria ou se deteria mais acentuadamente na relevância da avaliação dos dados religiosos em seu próprio plano de referência, identificando-se em sua abordagem, todavia, todas as demais preocupações que marcariam as orientações sociológicas, 
antropológicas e psicológicas. Parece que a proposta de Eliade tem o objetivo de corrigir lacunas delas, e isso naquilo que, em relação à compreensão do fenomenólogo da religião, elas teriam de reducionismo estritamente falando.

O segundo elemento que parece ainda mais relevador da necessidade de problematização do tratamento da proposta de Eliade como não reducionista é sua definição de sagrado. Conquanto formulada em visível polêmica com as perspectivas filosófico-evolucionistas da religião, que tenderiam a conceber a religião como prática inerente a determinado estágio da histórica da espécie humana, o que Eliade nega, a declaração “o 'sagrado’ é um elemento da estrutura da consciência, e não um estágio na histórica da consciência” (ELIADE, 1989, p. 10) constitui um momento particular de "redução" do sagrado ao universo antropológico (STUDSTILL, 2000, p. 183). Nesse sentido, sequer se pode falar de "experiência com o sagrado", mas de "experiência do sagrado", que, dado reduzirse o sagrado a um elemento da estrutura da consciência humana, faz dele um elemento constitutivo da própria experiência humana, mesmo que não necessariamente religiosa. Incontornavelmente humanas, experiências do sagrado atualizaram-se historicamente na forma de experiências religiosas, tanto quanto na forma de experiências não religiosas, de sorte que dificilmente não se pode conceber tratar-se de um reducionismo, ao modo como se classificam como reducionistas propostas teóricas em última análise do mesmo tipo. Parece adequado considerar que Eliade até se serve do conteúdo das próprias religiões em seu trabalho de análise e síntese do fenômeno religioso, mas não se resume a elaborar um sistema "com" tal conteúdo, mas "levando em conta" tal conteúdo, e isso não sem considerar que, constituindo o próprio sagrado não um ser, mas um elemento da estrutura da consciência humana, todo o conjunto das experiências humanas do sagrado constituem, em última análise, experiências de tipo feuerbachiano-durkheimiano. Não foi, portanto, sem propósito, que a epígrafe da presente seção - teorias não reducionistas da religião seja uma declaração nesse sentido reveladora de Eliade. 


\section{Conclusão}

Treze teorias ou quase teorias foram brevemente descritas. Chama atenção o fato de que se identifica sensível superioridade numérica de teorias reducionistas relativamente ao quantitativo das teorias não reducionistas, bem como o fato de que aquelas marcadamente não reducionistas concentrarem-se nos primórdios das pesquisas sobre religião, vinculando-se profundamente à questão da origem da religião. Sem ter esgotado o conjunto dos discursos sobre a religião discerníveis na literatura ${ }^{12}$, oito reducionistas e cinco não reducionistas foram tratadas. Considerando-se que a classificação da teoria de Eliade como não reducionista ou substantiva pode ser problematizada, algum leitor poderia estabelecer um cômputo de não oito para cinco, mas nove para quatro. Esta inclusive constituiria a inclinação do presente artigo, tivesse ele a pretensão de avaliação crítica das teorias, e não sua apresentação descritiva.

Nota-se um processo histórico de sofisticação das teorias. As teorias de Eliade, Durkheim, Geertz, por exemplo, são evidentemente mais sofisticadas do que as de Taylor, Marett ou Frazer. Por outro lado, a teoria de Feuerbach apresenta alto grau de sofisticação, a despeito de situar-se até um século de distância da teoria de Geertz, por exemplo. O que, todavia, não significa que ela não pode também ser aprofundada criticamente, já que não se concebem teorias como a de Marx, Freud e mesmo Durkheim sem o substrato feuerbachiano.

$\mathrm{O}$ artigo não esgota o rol das teorias que se poderiam recolher na literatura, conquanto muitas delas se sobreponham de modo perceptível. Mesmo que se sobreponham, acrescentam todavia elementos novos, que, até certo ponto, aprofundam as teorias das quais são claramente devedoras, como é o que se dá entre Marx e Feuerbach, por exemplo, ou Eliade e Durkheim.

\footnotetext{
${ }^{12}$ Por exemplo, a despeito de ter sido utilizado no presente artigo a obra em que é defendida, não se tratou em separado da teoria da religião como antropomorfismo (GUTRIE, 1993). Um espaço de comunicação mais apropriado certamente permitira o aumento da quantidade de teorias descritas. Além disso, não se tratou especificamente da teoria da religião de W. James e de Evans-Pritchard. 0 veículo não permite.
} 
Como partes do presente exercício, portanto, permanecem duas tarefas: a) a ampliação do leque de teorias e quase teorias descritas (e seu necessário aprofundamento); e b) a avaliação crítica das teorias e quase teorias colecionadas.

\section{REFERÊNCIAS}

ALETTI, M. A figura da ilusão na literatura psicanalítica da religião. Psicologia, v. 15, n. 3, p. 163-190, 2004.

ALVES SÁ, A. M. Religião e sociedade. Considerações a partir de Marx e Freud. Colloquium Humanarum, v. 9. n. 1, p. 69-83, 2012.

AMÉRICO, E. V. Iúri Lotman e a Escola de Tártu-Moscou. Galaxia, n. 29, p. 123-140, 2015 .

ANTONOV, K. M. The perception of the ideas of Fr. Wilhelm Schmidt in Russia.The context of the History of Russian religious studies. Anthropos, n. 113, p. 1-10, 2018.

ARAÚJO, M. A. M. Antropologia na missão: relações entre a etnologia confessional de padre Schmidt e a antropologia acadêmica. Religião e Sociedade, v. 33, n. 1, p. 30-49, 2013 .

ARISTÓTELES. Política. São Paulo: Folha de São Paulo, 2010.

ARKUSH, A. Voltaire on Judaism and Christianity. Association for Jewish Studies Review, v. 18, n. 1, p. 223-243, 1993.

ARON, R. As etapas do pensamento sociológico. São Paulo: Martins Fontes, 2002.

ASAD, T. Formations of the secular: Christianity, Islam, Modernity. Stanford:

Stanford University Press, 2003.

ASMANN, J. Religion and cultural memory. Stanford: Stanford University Press, 2006.

BECKER, M. R. M. Ensino religioso entre catequese e ciências da religião: uma avaliação comparativa da formação dos professores do ensino religioso no Brasil e da aprendizagem inter-religiosa na Alemanha em busca de um ensino religioso interteológico e interdisciplinar. Tese (Doutorado em Educação) - Universidade Federal do Ceará, Fortaleza, 2010.

BENGTSON, D. R. R. R. Marrett and the Study of Religion. Journal of the American Academy of Religion, v. 47, n. 4, p. 645-659, 1979. 
BERGER, P. Some second thoughts on substantive versus functional definitions of religion. Journal for the Scientific Study of Religion, v. 13, n. 2, p. 125-133, 1974.

BIANCHI, A. A mundanização da Filosofia. Marx e as origens da crítica política. Trans/Form/Ação, v. 29, n. 2, p. 43-64, 2006.

BIRD-DAVID, N. “Animism” revisited. Personhood, environment, and relational epistemology. Current Anthropology, v. 40, p. 67-91, 1999.

BROWN, L.; WALKER, W. H. Prologue: Archaeology, Animism and Non-Human Agents. Journal of Archaeological Method and Theory, v. 15, n. 4, p. 297-299, 2008.

BRUBAKER, R. Religious dimensions of political conflict and violence.

SociologicalTheory, v. 33, n. 1, p. 1-19, 2015.

CAMPOS, L. Feuerbach: transcender para o aquém. Trilhas Filosóficas, v. 7, n. 2, p. 6178, 2014.

CASTRO, E. B. V. de. Exchanging perspectives: the transformation of objects into subjects in Amerindian ontologies. Common Knowledge, v. 10, n. 3, p. 463-484, 2004.

DAVID, S. N. Freud e a religião. Rio de Janeiro: Jorge Zahar Editor, 2003.

DURKHEIM, E. The Elementary forms of the religious life. New York: The Macmillan Company, 1915.

DURKHEIM, E.The Elementary forms of the religious life. New York: Fredd Press, 1965 .

ELIADE, M. Origens. História e sentido na religião. Lisboa: Edições 70, 1989.

ELIADE, M. Tratado de história das religiões. Lisboa: Cosmos, 1990.

FEUERBACH, L. A essência do Cristianismo. 2. ed. Campinas: Papirus, 1997.

FEUERBACH, L. A essência do Cristianismo. Petrópolis: Vozes, 2012.

FEUERBACH, L. Teses provisórias para a reforma da Filosofia. In: FEUERBACH, L. Filosofia da sensibilidade. Escritos (1839-1846). Lisboa: Centro de Filosofia da Universidade de Lisboa, 2005. p. 85-100.

FREUD, S. Totem e tabu. Rio de Janeiro: Imago, 1996.

GEERTZ, C. A interpretação das culturas. Rio de Janeiro: LTC, 2008.

GEERTZ, C. The interpretation of cultures. New York: Basic Books, 1973.

GLASSE, J. Barth on Feuerbach. The Harvard Theological Review, v. 57, n. 2, p. 6996, 1964. 
GUTRIE, S. E. Faces in the clouds. A new theory of religion. Oxford: Oxford University Press, 1993.

HALL, J. R. Religion and violence. Social processes in comparative perspective. In: DILLON, M. (ed). Handbook of the Sociology of Religion. Cambridge: Cambridge University Press, 2003. p. 359-384.

HARRIS, M. Cultural Anthropology. New York: Harper and How, 1983.

HUME, D. História natural da religião. São Paulo: UNESP, 2004.

LACAN, J. O triunfo da religião. Precedido de "Discurso aos Católicos". Rio de Janeiro: Jorge Zahar, 2005.

LEPAPE, P. Voltaire. Nascimento dos intelectuais no século das luzes. Rio de Janeiro: Jorge Zahar Editor, 1995.

LIMA FILHO, J. E. Antropologia, ética e política em "A Essência do Cristinismo" de Ludwig Feuerbach. Tese (Doutorado em Filosofia) - Universidade Federal do Ceará, Fortaleza, 2017.

LOPES, J. L. C. A teologia e o idealismo como inversão da ordem concreto/abstrato em Feuerbach. Revista Reflexões, v. 4, n. 7, p. 124-135, 2015.

LUZ, M. da. Considerações sobre a correlação entre religião e violência. Conscientia, v. 12, n. 3, p. 267-277, 2008.

MACIEL, K. D. de S. A.; ROCHA, Z. de J. B. Freud e a religião: possibilidades de novas leituras e construções teóricas. Psicologia, Ciência e Profissão, v. 28, n. 4, p. 742-753, 2008.

MALINOWSKI, B. Argonautas do Pacífico ocidental. Um relato do empreendimento e da aventura dos nativos nos Arquipélagos da Nova Guiné melanésia. São Paulo: Abril Cultural, 1978.

MARETT, R. R. Pre-Animistic Religion. Folklore, v. 11, n. 2, p. 162-184, 1900.

MARX, F. Contribución a la crítica de la filosofía del derecho de Hegel. In: MARX, K.; ENGELS, F. Sobre la religión. 2. ed. Salamanca: Sígueme, 1979a. p. 93-106.

MARX, K. Tesis sobre Feuerbach. In: MARX, K.; ENGELS, F. Sobre la religión. 2. ed. Salamanca: Sígueme, 1979b. p. 159-161.

MÉSZÁROS, I. A teoria da alienação em Marx. São Paulo: Boitempo, 2006.

MIRANDA, L. L. A cultura da imagem e uma nova produção subjetiva. Psicologia Clínica, v. 19, n. 1, p. 25-39, 2007. 
MORAIS, J. E. T. A teologia antropológica de Ludwig Feuerbach. Revista de Cultura Teológica, v. 22, n. 83, p. 127-139, 2014.

MOTA, V. de O. As bases da religião natural em Voltaire. Revista Trágica: estudos de filosofia da imanência, v. 7, n. 1, p. 95-108, 2014.

NEGRÃO, L. N. Nem “jardim encantado" nem "clube dos intelectuais desencantados”. Revista Brasileira de Ciências Sociais, v. 20, n. 59, p. 23-36, 2005.

NIELI, R. Wittgenstein: from mysticism to ordinary language: A Study of Viennese Positivism and the Thought of Ludwig Wittgenstein. New York: New York University Press, 1987.

NOGUEIRA, P. A. de S. Religião como texto. Contribuições da semiótica da cultura. In: NOGUEIRA, P. A. de S. (org.). Linguagens da religião. Desafios, métodos e conceitos centrais. São Paulo: Paulinas, 2012. p. 13-20.

NOGUEIRA, P. A. de S. Traduções do intraduzível: a semiótica da cultura e o estudo de textos religiosos nas bordas da semiosfera. Estudos de Religião, v. 29, n. 1, p. 102-123, 2015 .

OLIVEIRA, A. S. Desvendando a religião e as religiões mundiais em Max Weber.

Horizonte, v. 7, n. 14, p. 136-155, 2009.

PALS, D. L. Eight theories of religion. Oxford: Oxford University Press, 2006.

PALS, D. L. Nove teorias da religião. Petrópolis: Vozes, 2019.

PANOURGIÁ, N. Interview with Clifford Geertz. Anthropological Theory, v. 2, n. 4, p. 421-431, 2002.

PIEPER, F. Religião: limites e horizontes de um conceito. Estudos de Religião, São Bernardo do Campo, v. 33, n. 1, p. 5-35, 2019.

PIERUCCI, A. F. Religião como solvente - uma aula. Novos Estudos, n. 75, p. 111-127, 2006.

REDYSON, D. Ludwig Feuerbach e o jovem Marx: a religião e o materialismo antropológico dialético. Argumentos, v. 3, n. 5, p. 7-13, 2011.

RIBEIRO, O. L. Teologia no divã. Pistis e Praxis, v. 1, n. 1, p. 199-218, 2009.

RODRIGUES, A. M. Religião, teologia e antropologia: o confronto entre Karl Barth e Ludwig Feuerbach. Horizonte, Belo Horizonte, v. 7, n. 14, p. 156-169, 2009.

ROSA, M. Psicologia da religião. 3. ed. Rio de Janeiro: JUERP, 1992.

SAMPAIO, B. A.; FREDERICO, C. Dialética e materialismo: Marx entre Hegel e Feuerbach. Rio de Janeiro: Editora UFRJ, 2009. 
SANDVIK, L. P. Showcasing Shinto. The reinvention of Shinto as an ecological religion. Master's Degree Thesis in History of Religion. Oslo: University of Oslo, 2011.

SHELESTIUK, H. V. Semantics of symbol. Journal of the International Association for Semiotic Studies, n. 144, p. 233-259, 2003.

SILVA FILHO, P. G. Considerações teóricas em torno do reducionismo funcionalista em Ciências da Religião. Rever, São Paulo, n. 4, p. 43-72, 2004.

SOUZA, J. C. de. Moses Hess como o espectro feuerbachiano de Marx. Philósophos, v. 18, n. 1, p. 191-218, 2013.

SOUZA, R. F. de. Símbolos, memória e a semiótica da cultura: a religião entre a estrutura e o texto. Estudos de Religião, São Bernardo do Campo, v. 29, n. 1, p. 70-86, 2015.

STUDSTILL, R. Eliade, Phenomenology, and the Sacred. Religious Studies, v. 36, n. 2, p. 177-194, 2000.

TILLICH, P. Dinâmica da fé. 4. ed. São Leopoldo: Sinodal, s/d.

TILLICH, P. La significación de la historia de las religiones para el teólogo sistemático. In: TILLICH, P. El futuro de las religiones. Buenos Aires: Megápolis, 1977.

TYLOR, E. B. Primitive culture. Researches into the development of mythology, philosophy, religion, art and custom. London: John Murray, 1871. v. 2.

UGLIK, J. Ludwig Feuerbach's conception of the religious alienation of man and Mikhail Bakunin's philosophy of negation. Studies in East European Thought, v. 62, n. 1, p. 19-28, 2010.

VÁSQUEZ, Manuel A. More than belief: a materialist theory of religion. New York: Oxford University, 2011.

VOLTAIRE. Deus e os homens. São Paulo: Martins Fontes, 1995.

WEBER, M. Economia e sociedade. Brasília: Editora Universidade de Brasília, 2000.

WEBER, M. The religion of India. The Sociology of Hinduism and Buddhism. Illinois: The Free Press, 1958.

WEBER, M. The Sociology of Religion. Boston: Beacon, 1963.

WINTHROP, R. H. Dictionary of Concepts in Cultural Anthropology. New York: Greenwood Press, 1991.

WRIGHT J. D.; KHOO, Y. Empirical perspectives on religion and violence. PsyArXivPreprints, 2019. Disponível em: https://psyarxiv.com/gzspe. Acesso em: 19 ago. 2019. 